Innovative research is being conducted into reintroduction techniques for establishing another migratory flock of Whooping Cranes. Sandhill Cranes are being taught to migrate with an ultra-light aircraft to establish new migration routes. Early results are encouraging but more work needs to be done before the recovery team endorses the technique as a viable option for establishing new breeding and wintering areas for Whooping Cranes. Areas under consideration for such a migratory flock include Manitoba and the southeast United States.

In the mean time the AransasWood Buffalo flock continues its slow but steady increase. The population which once numbered only 15 birds reached a high of 146 birds in 1989 but was only able to break the 150 mark this past year. The stability of the winter range in Texas continues to cause concern for the recovery team. The sooner we are able to encourage Whooping Cranes to winter in more than one locale, through establishing additional populations, the safer the survival of the Whooping Crane becomes.

Brian Johns, Canadian Wildlife Service, Saskatoon, SK.

\section{GREAT BLUE HERON EATING A RICHARDSON'S GROUND SQUIRREL}

While checking on his cattle on pasture, our neighbour, Ernie Quintal, noticed a Great Blue Heron in a stalking pose over a gopher (Richardson's Ground Squirrel), stunning it, and then grasping it in its beak. It then flew to a nearby cattle watering hole (actually a rather shallow pothole) where it upended the gopher to grasp it by its head. It then dunked the gopher in the muddy bottom of the pothole. This operation was repeated four or five times until the gopher was drowned and covered with gooey mud. The heron then raised and opened its beak and proceeded to swallow this adult gopher with apparent ease.

The above procedure was later witnessed by myself, accompanied by Ernie and several other people, at various times during a two-week period. As far as we could ascertain, it was always the same heron as it would drive other herons away if they entered on its turf. Ernie observed several gophers being consumed in a single morning. Later in the season, as water levels rose, the heron would take its kill to other more convenient water holes.

The pasture area was literally a "holey land" occupied by many of their immature offspring. Later in the summer, the young gophers were seen to be eaten directly without the drowning and mudding process; presumably because they were easier to swallow.

Water levels in this area have been very high this year, resulting in receding shorelines and possibly a shortage of suitable feeding sites for herons. Several other observations of gopher-eating herons have been reported.

The particular sighting captured on the enclosed slides took place at Ernie Quintal's farm, near Lac La Biche, Alberta: NE 1/4 Section 1-6713-W.4 on 25 June 1996.

Jerry Sykes, Lac la Biche, AB. 


\section{Great Blue Heron drowning and swallowing a Ground Squirrel}
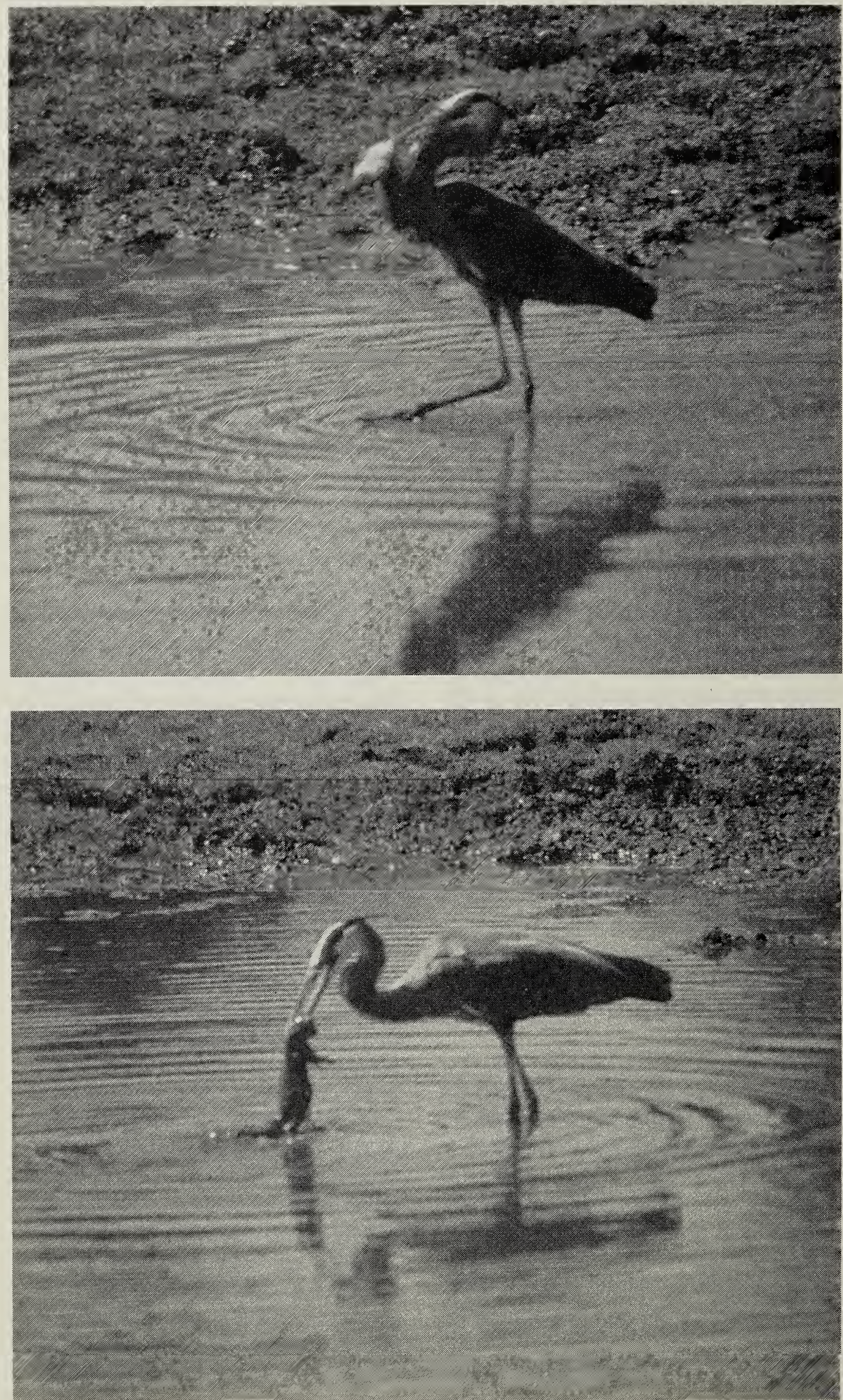

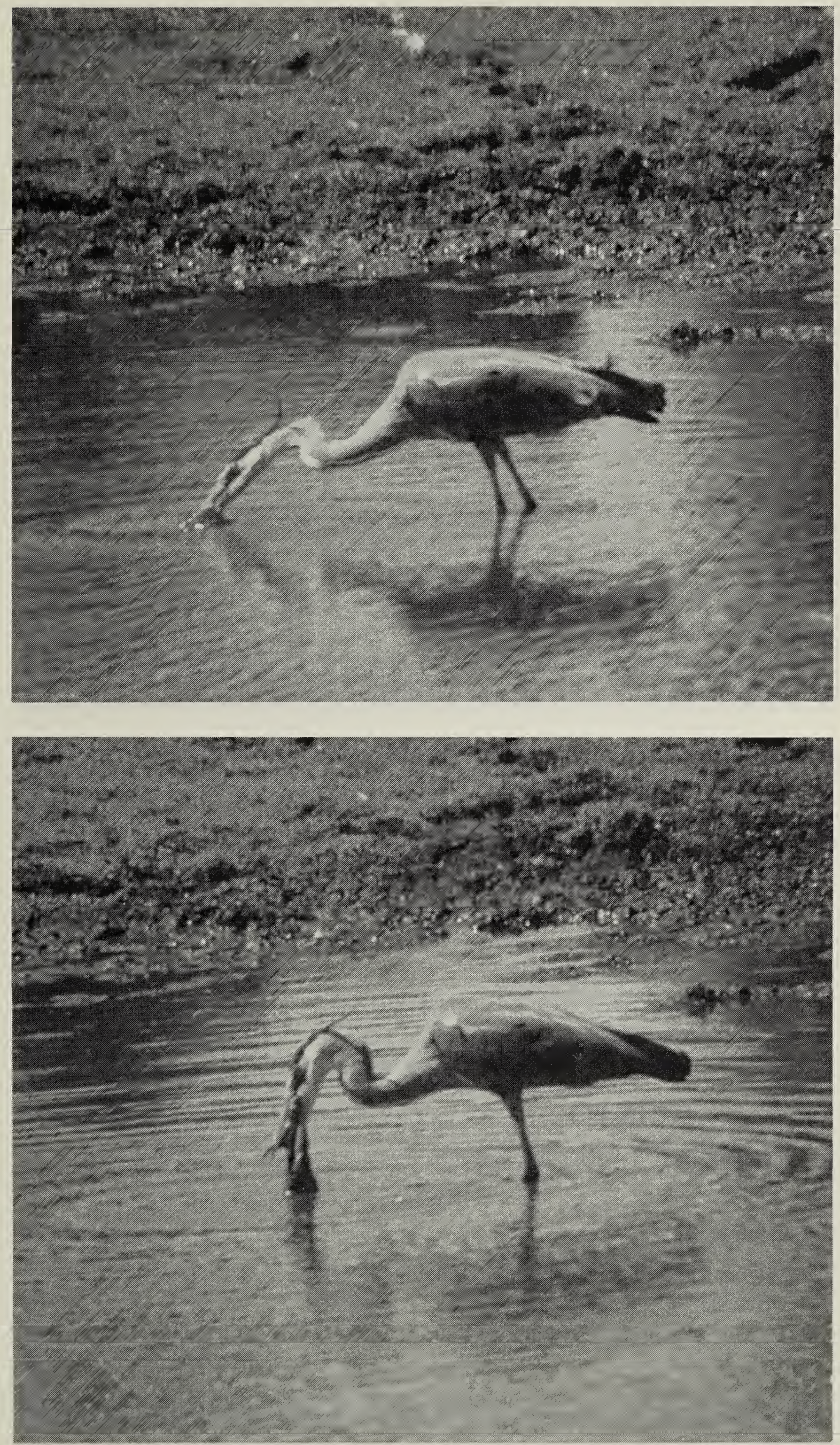

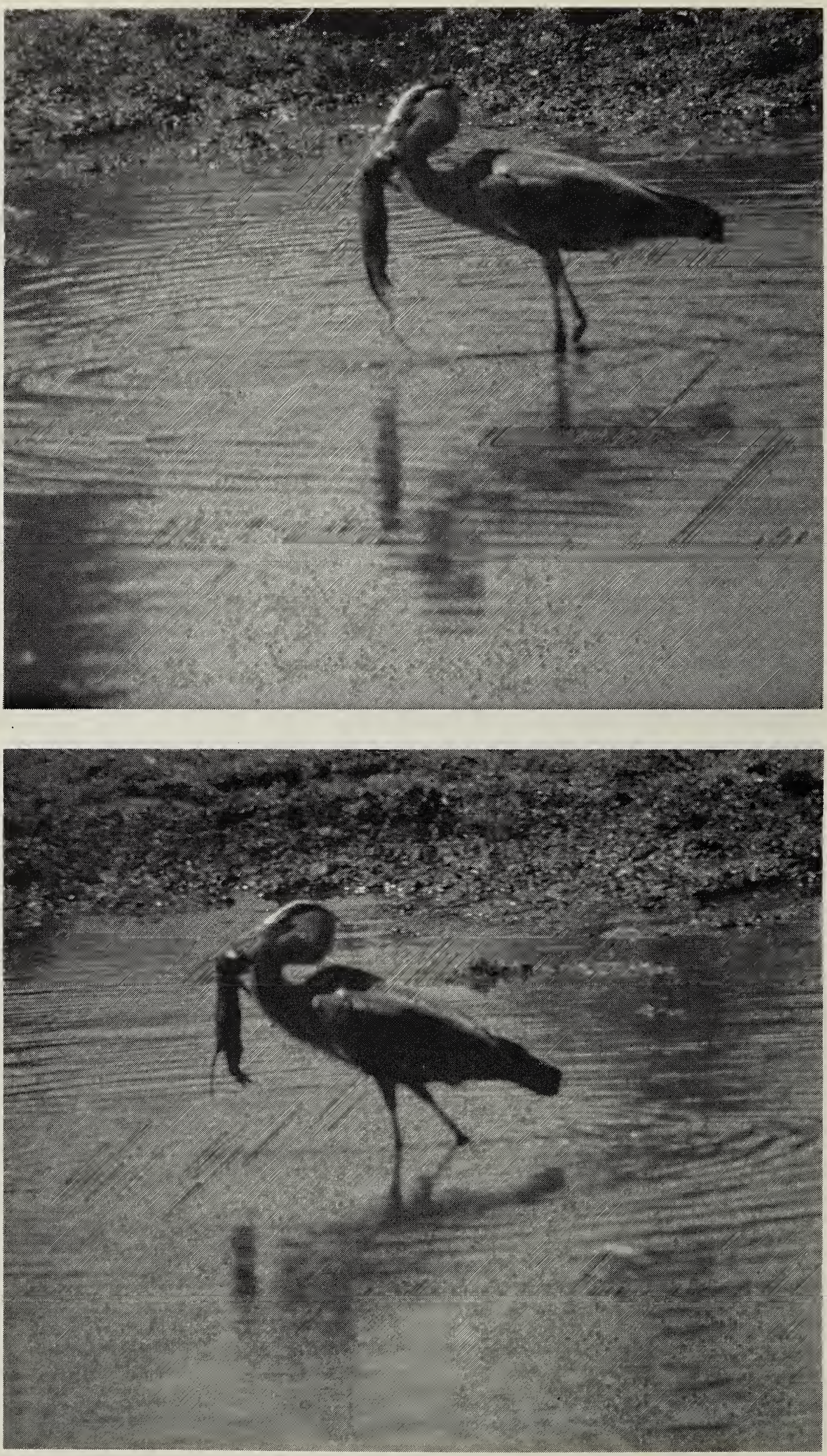

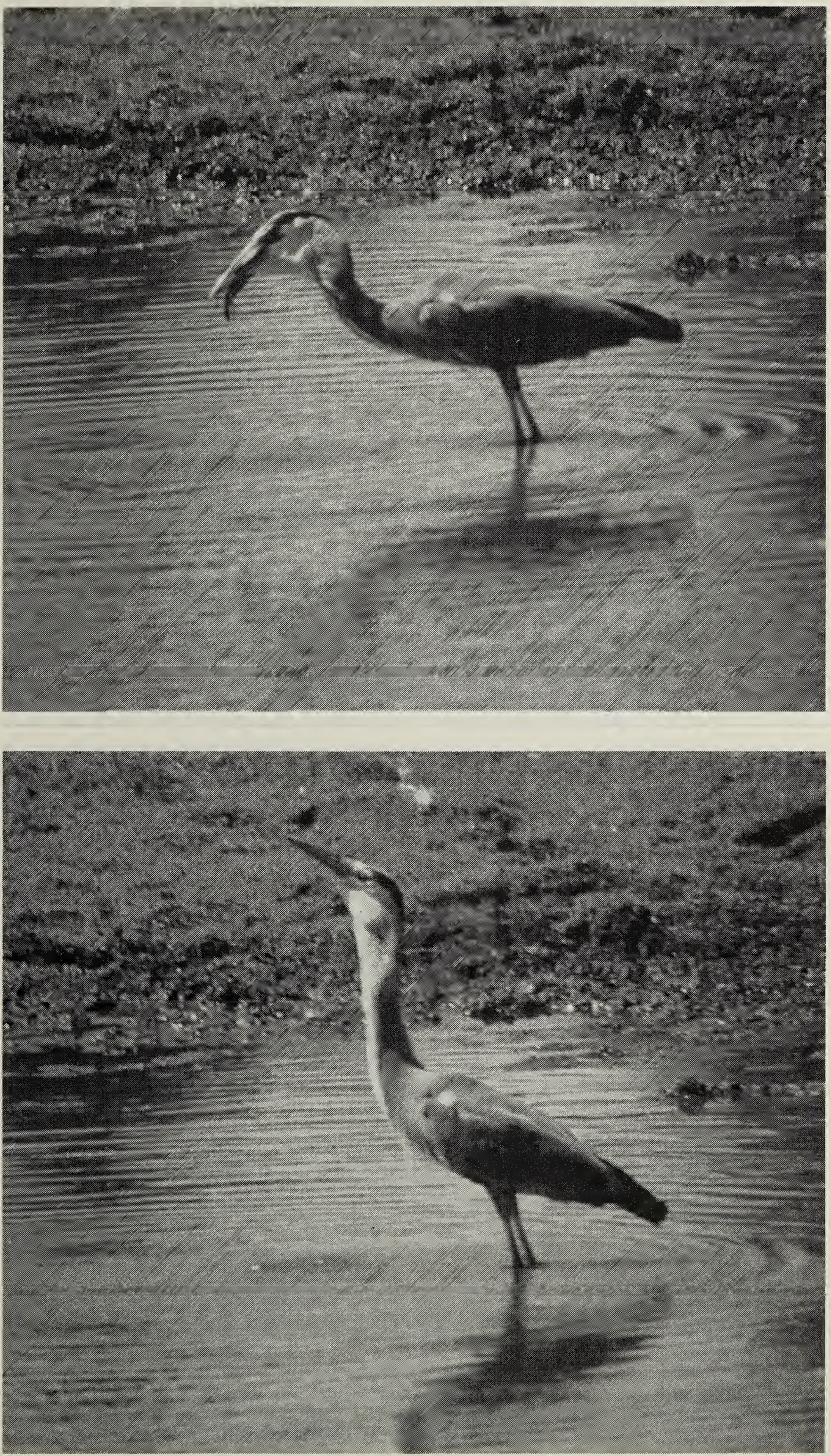

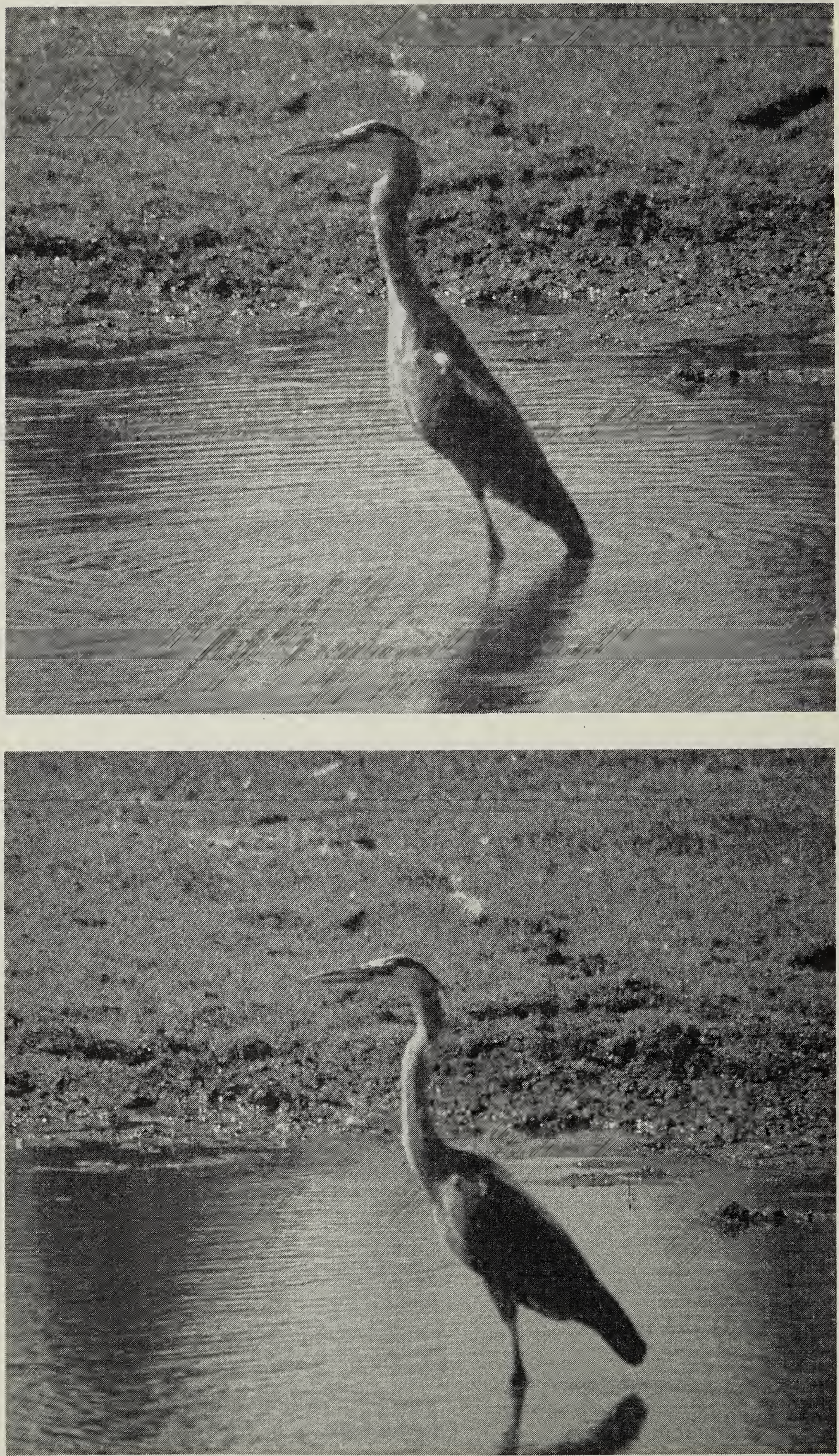